\title{
PERKEMBANGAN PERTUMBUHAN TEGAKAN SETELAH PENEBANGAN DI AREAL IUPHHK-HA PT. DIAMOND RAYA TIMBER
}

\author{
The Development of Stand Growth after Logging in IUPHHK-HA PT Diamond Raya Timber Areal
}

\author{
Istomo $^{1}$ dan Mega Damayanti ${ }^{2}$
}

(Diterima Juli 2017/Disetujui Februari 2020)

\begin{abstract}
Peat swamp forest management which is less precise will cause diversity on peat swamp forest decreased, in particular endemic species that can only be grown on peat swamp forest. So the research about the condition of peat swamp forest after logging needs to be done. This research aims to analyze species diversity and the development of stand growth after logging as well as analyze stability of species diversity in logged forest IUPHHK-HA PT Diamond Raya Timber. The data collected by combination of path method and grid line method. This research located in biodiversity strip (Protected Area) and logged over area (LOA) 2013, logged over area (LOA) 2015 and logged over area (LOA) 2016. The results showed that condition of the forest in the studied area was already quite stable with index of evenness ranged at 0.56-0.94. There is decreasin stand potential compared with biodiversity strip areal. Stand potential in biodiversity was 254,06 m3/ha, LOA 2013 was 99,72 m3/ha, LOA 2015 was 53,57 m3/ha and LOA 2016 was 58,41 m3/ha.
\end{abstract}

Keywords: peat swamp forest, stability, stand potential, LOA, diversity

\section{PENDAHULUAN}

Hutan rawa gambut merupakan salah satu tipe hutan tropika yang terdapat di Indonesia. Hutan rawa gambut mempunyai karakteristik tumbuhan maupun hewan yang khas yaitu komunitas yang mampu beradaptasi dengan kondisi hutan yang miskin unsur hara dan tergenang air yang cukup. Hutan rawa gambut memiliki jenis-jenis pohon yang bernilai ekonomi tinggi dan endemik seperti jenis pohon ramin (Gonystylus bancanus) dan meranti rawa (Shorea teysmanniana) yang menjadi primadona pohon pada hutan rawa gambut. Kegiatan pengelolaan hutan rawa gambut yang kurang tepat akan menyebabkan berkurangnya keanekaragaman jenis tanaman yang ada pada hutan rawa gambut khususnya jenis-jenis endemik yang hanya dapat tumbuh pada hutan rawa gambut. Untuk pengelolaan hutan yang semakin baik maka diperlukan informasi mengenai struktur tegakan dan jenis-jenis yang terdapat pada areal hutan rawa gambut. Hal ini berguna pula untuk mengetahui bagaimana pemulihan kondisi tegakan setelah terjadinya penebangan. Kegiatan penebangan dapat mempengaruhi regenerasi alam terutama pada tingkat semai dan pancang (Ewel dan Conde, 1980).

Salah satu indikator pemulihan hutan secara lestari yaitu terciptanya regenerasi permudaan alam yang dicirikan pertumbuhan permudaan alam dan ketahanan keanekaragaman jenisnya. Kondisi permudaan

\footnotetext{
${ }^{1}$ Dosen Departemen Silvikultur, Fakultas Kehutanan Institut Pertanian Bogor

* Penulis korespondensi: e-mail: istomo19@gmail.com

2 Mahasiswa Departemen Silvikultur, Fakultas Kehutanan Institut Pertanian Bogor
}

pascapanen kemungkinan telah stabil pertumbuhannya sehingga informasi komposisi, sebaran, kerapatan, dan keanekaragaman jenisnya dapat bermanfaat untuk pertimbangan perencanaan pengelolaan hutan bekas tebangan selanjutnya.

Studi mengenai kondisi tegakan pada LOA perlu dilakukan untuk mengetahui keanekaragaman jenis permudaan dan pertumbuhan tegakaan yang terdapat pada areal pasca tebangan. Serta untuk mengetahui stabilitas keanekaragaman jenis LOA. Hasil studi diharapkan dapat bemanfaat untuk merencanakan pengayaan pada areal yang kurang permudaan dan untuk menentukan jenis-jenis yang akan ditanam agar mendapatkan nilai ekonomi yang tinggi. Penelitian ini bertujuan untuk mengkaji keanekaragaman jenis dan perkembangan pertumbuhan tegakan setelah penebangan dan mengkaji kestabilan keanekaragaman jenis pada hutan bekas tebangan di aeral IUPHHK-HA PT. Diamond Raya Timber.

\section{METODE PENELITIAN}

\section{Waktu dan Lokasi Penelitian}

Kegiatan penelitian ini dilaksanakan pada bulan April sampai dengan bulan Mei 2016 di Biodiversity strip serta Log Over Area (LOA) 2013, Log Over Area (LOA) 2015, dan Log Over Area (LOA) 2016 IUPHHK-HA PT. Diamond Raya Timber Provinsi Riau.

\section{Alat dan Bahan}

Penelitian ini menggunakan petak kerja/peta lokasi, pita ukur 30 meter, phiband, Global Positioning Satelite 
(GPS), haga hypsometer, kompas, tambang, patok, sasak, koran, olastik sample, alkohol $70 \%$, buku identifikasi tumbuhan, tally sheet, kertas label, kamera digital serta alat tulis.

Bahan yang digunakan pada penelitian ini adalah data primer dan data skunder yang dikumpulkan dilokasi penelitian. Data primer diperoleh melalui pengukuran maupun pengamatan dilokasi penelitian, meliputi data vegetasi yaitu data pohon, tiang, pancang, semai, dan tumbuh-tumbuhan non pohon. Data semai, pancang, dan tumbuh-tumbuhan non pohon diambil nama jenis dan jumlah individunya, sedangkan untuk data tiang dan pohon diambil nama jenis, jumlah individu, diukur diameter setinggi dada (dbh), tinggi bebas cabang (TBC), Tinggi total (TT), serta posisi tiang dan pohon terhadap sumbu X dan Y untuk pembuatan Diagram Profil Pohon.

\section{Prosedur Penelitian}

\section{Penentuan lokasi studi}

Lokasi pengambilan data dan pengukuran dilakukan pada kawasan Biodiversity strip serta areal tebangan LOA 2013, LOA 2015, dan LOA 2016 IUPHHK-HA PT. Diamond Raya Timber Provinsi Riau. Petak contoh pengamatan di tempatkan pada lokasi tersebut, dengan memperhatikan keterwakilan karakteristik tumbuhan yang diukur, biaya, waktu dan tenaga yang dibutuhkan. Ukuran petak contoh ditetapkan $20 \mathrm{~m}$ x $400 \mathrm{~m}$ yang dibagi menjadi 25 subpetak dengan total jumlah jalur yaitu 4 jalur yang terbagi dalam 4 lokasi.

Pada petak $2 \mathrm{~m}$ x $2 \mathrm{~m}$ untuk pengamatan semai dan tumbuhan bawah, petak $5 \mathrm{~m}$ x $5 \mathrm{~m}$ untuk pengamatan tingkat pancang, petak $10 \mathrm{~m} \times 10 \mathrm{~m}$ untuk pengamatan tiang, petak $20 \mathrm{~m}$ x $20 \mathrm{~m}$ untuk pengamatan pohon.

Sumbu X memetakan posisi pohon terhadap sumbu X, sumbu Y memetakan posisi pohon terhadap sumbu Y. Metode pengambilan data yang dilakukan untuk analisis vegetasi disajikan pada Gambar 2.

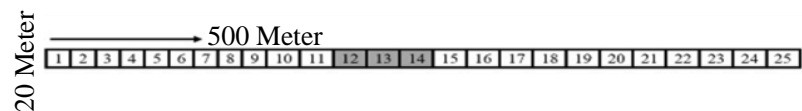

Keterangan: sub-petak 12, 13 dan 14 sekaligus untuk pengambilan data profil tajuk.

Gambar 1 Petak contoh penelitian pada lokasi pengamatan

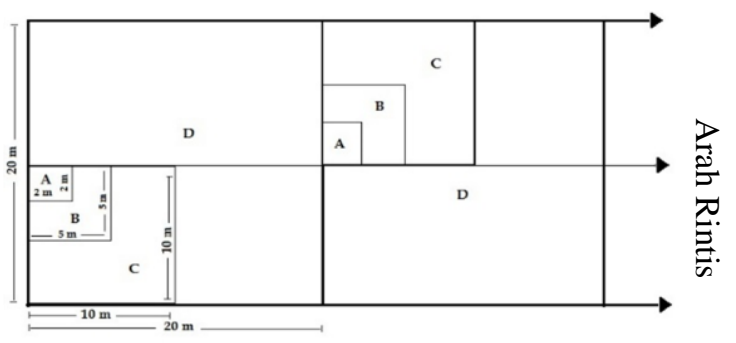

Gambar 2 Ilustrasi metode analisis tegakan pada setiap subpetak

\section{HASIL DAN PEMBAHASAN}

Komposisi jenis pada suatu tegakan menunjukan keberadaan jenis-jenis pohon dalam tegakan hutan. Informasi mengenai komposisi jenis digunakan untuk menentukan pengelolaan hutan. Pemanenan kayu dapat mempengaruhi komposisi jenis pada hutan bekas tebangan. Dengan penerapan sistem silvikultur yang sesuai dan teknik pemanenan yang terkendali diharapkan regenerasi alami berjalan dengan baik dan kerusakan dapat ditekan.

Berdasarkan Tabel 1 jumlah jenis semai dan tumbuhan bawah lebih tinggi bila dibandingkan dengan tingkat pancang, tiang dan pohon. Banyaknya jumlah tingkat semai dan tumbuhan bawah menunjukan tingkat survival dari tingkat ini ketingkat pertumbuhan lainnya. Jumlah jenis semua tingkat pertumbuhan dari semai, pancang, tiang dan pohon pada areal LOA 2015 dengan areal LOA 2013 memiliki jumlah jenis yang sama, jika dibandingkan dengan areal LOA 2016 maka jumlah jenis pada LOA 2016 terjadi penurunan. Hal ini diduga karena adanya faktor gangguan dari kegiatan penebangan. Karena lokasi LOA 2016 areal yang terbilang baru selesai penebangan.

Peranan suatu jenis dalam sebuah komunitas dapat dilihat dari besarnya nilai Indeks Nilai Penting (INP). Berdasarkan Tabel 2 jenis yang mendominasi pada berbagai komunitas dan berbagai tingkat pertumbuhan berbeda-beda. Pada areal biodiversity strip pada tingkat pancang didominasi oleh Palaquium obovatum dengan presentasi nilai INP sebesar 45,53\%, pada tingkat tiang didominasi oleh Artocarpus teysmanii dengan presentasi INP sebesar 89,7 \%, serta pada tingkat pohon didominasi oleh Shorea Uliginosa dengan presentasi INP sebesar 31,43\%. Pada LOA 2015 pada tingkat pancang dan tiang didominasi oleh Eugenia sp dengan presentasi INP sebesar $47,7 \%$ dan $56,37 \%$ serta pada tingkat pohon didominasi jenis Camnosprema mycrophylla dengan presentase INP sebesar 38,87\%. Pada LOA 2013 pada tingkat pancang didominasi oleh jenis Santiria griffithii dengan presentasi nilai INP sebesar 26,1 \%, pada tingkat tiang didominasi oleh jenis Artocarpus teysmanii dengan presentasi INP sebesar 97,42\%, serta pada tingkat pohon didominasi oleh jenis Mangifera foetida dengan presentasi INP sebesar 41,67 \%. Pada LOA 2016 pada tingkat pancang dan tiang didominasi oleh Eugenia $s p$ dengan presentasi INP sebesar $27,18 \%$ dan 78,22\% serta pada tingkat pohon didominasi jenis Camnosprema mycrophylla dengan presentase INP sebesar 48,39\%. Hal ini disebabkan jenis tersebut mempunyai kesesuaian tempat tumbuh yang baik serta mempunyai daya tahan tumbuh yang baik pula jika dibandingkan dengan jenis lain yang ada dalam komunitas tersebut. Selain itu INP berpengaruh terhadap nilai indeks yang digunakan didalam analisis vegetasi.

Pola dominansi jenis dalam suatu tegakan dapat dilihat dari nilai Indeks Dominansi (C). Berdasarkan hasil perhitungan Indeks Dominansi jenis (Tabel 3) diperoleh nilai $\mathrm{C}$ yang kurang dari 1 untuk semua tingkat pertumbuhan baik pada biodiversity strip maupun pada LOA. Hal ini menunjukan bahwa tegakan biodiversity strip maupun pada LOA tidak didominansi oleh jenis tertentu pada berbagai tingkat pertumbuhan. 
Berdasarkan Tabel 4 dapat dilihat nilai Indeks kekayaan Margallef (R1) disetiap areal berbeda-beda. Pada tingkat pertumbuhan semai nilai tertinggi pada LOA 2013 dengan nilai 2,95 dan terendah pada biodiversity strip dengan nilai 1,92. Pada tingkat pertumbuhan pancang nilia tertinggi pada LOA 2015 dengan nilai 4,89 dan terendah pada LOA 2013 dengan nilai sebesar 3,88 . Pada tingkat pertumbuhan tiang nilai tertinggi pada LOA 2016 dengan nilai sebesar 8,3 dan terendah pada LOA 2013 dengan nilai sebesar 2,23. Pada tingkat pertumbuhan pohon nilai tertinggi pada LOA 2016 dengan nilai sebesar 6,17 dan terendah pada biodiversity strip dengan nilai sebesar 4,41. Perbedaan nilai indeks kekayaan Margallef (R1) pada masingmasing kondisi hutan dipengaruhi oleh jumlah jenis dan jumlah individu perjenis yang ditemukan pada komunitas.

Nilai Indeks keanekaragaman pada tingkat semai pada keseluruhan lokasi pengamatan berkisar antara
1,55-1,93 yang termasuk dalam katagori rendah. Untuk tingkat pertumbuhan pancang, tiang dan pohin berkisar antara $1,82-2,83$ yang termasuk kedalam katagori sedang. Secara umum nilai $\mathrm{H}$ pada biodiversity strip termaksud tinggi bila dibandingkan dengan LOA. Nilai H' pada LOA 2015 memiliki nilai H' lebih tinggi bila dibandingkan dengan nilai H' pada LOA lainnya. Hal ini dapat disebabkan karna gangguan yang terjadi pada LOA 2015 tidak terlalu besar sehingga keanekaragaman jenis pada areal tersebut cukup tinggi.

Nilai indeks kemerataan (Tabel 4) pada tingkat pertumbuhan semai, tiang dan pohon memiliki nilai berkisar dar 0,66 - 0,94 yang tergolong dalam kategori tinggi. Pada tingkat pertumbuhan pancang memiliki nilai berkisar dari 0,56 - 0,58 pada LOA dan masuk kedalam kategori sedang. Nilai indeks kemerataan pada LOA tidak berbeda jauh dengan nilai indeks kemerataan pada biodiversity strip. Hal ini menunjukan bahwa penyebaran

Tabel 1 jumlah jenis dalam petak ukur pada Log Over Area dan biodiversity strip.

\begin{tabular}{lcccc}
\hline \multirow{2}{*}{ Tingkat Pertumbuhan } & \multicolumn{4}{c}{ Jumlah Jenis } \\
\cline { 2 - 4 } & BDS & LOA 2013 & LOA 2015 & LOA 2016 \\
\hline Semai & 19 & 19 & 25 & 17 \\
Pancang & 11 & 8 & 13 & 9 \\
Tiang & 18 & 19 & 15 & 20 \\
Pohon & 14 & 19 & 14 & 14 \\
\hline
\end{tabular}

Keterangan: $\mathrm{BDS}=$ Biodiversity strip (dilindungi), LOA = Log Over Area

Tabel 2 Nilai INP terbesar yang dimiliki tumbuhan pada berbagai tingkat pertumbuhan pada LOA dan biodiversity strip

\begin{tabular}{llll}
\hline Kondisi hutan & Tingkat Pertumbuhan & Nama Jenis & INP $(\%)$ \\
\hline BDS & Semai & Eugenia $s p$ & 60,19 \\
& Pancang & Palaquium obovatum & 45,63 \\
& Tiang & Artocarpus teysmanii & 89,7 \\
& Pohon & Shorea uliginosa & 31,43 \\
\hline LOA 2013 & Semai & Eugenia sp & 70,44 \\
& Pancang & Santiria griffithii & 26,1 \\
& Tiang & Eugenia sp & 97,42 \\
& Pohon & Mangifera foetida & 41,67 \\
\hline LOA 2015 & Semai & Lindera subumbelliflora & 49,67 \\
& Pancang & Eugenia sp & 47,7 \\
& Tiang & Eugenia sp & 56,37 \\
& Pohon & Camnosprema mycrophylla & 38,87 \\
\hline LOA 2016 & Semai & Lindera subumbelliflora & 79,02 \\
& Pancang & Eugenia sp & 27,18 \\
& Tiang & Eugenia sp & 78,22 \\
& Pohon & Lindera subumbelliflora & 48,39 \\
\hline
\end{tabular}

Keterangan: BDS = Biodiversity strip (dilindungi), LOA = Log Over Area

Tabel 3 Nilai indeks dominansi pada berbagai tingkat permudaan pada Log Over Area dan biodiversity strip

\begin{tabular}{ccccc}
\hline \multirow{2}{*}{ Tingkat Pertumbuhan } & \multicolumn{4}{c}{ Kondisi Hutan } \\
\cline { 2 - 5 } & BDS & LOA 2013 & LOA 2015 & LOA 2016 \\
\hline Semai & 0,17 & 0,17 & 0,15 & 0,21 \\
Pancang & 0,09 & 0,08 & 0,12 & 0,08 \\
Tiang & 0,1 & 0,18 & 0,1 & 0,14 \\
Pohon & 0,07 & 0,08 & 0,07 & 0,08 \\
\hline
\end{tabular}

Keterangan: BDS = Biodiversity strip (dilindungi), LOA = Log Over Area 
jenis pada setiap areal lokasi pengamatan tersebar merata.

Perbandingan antara komunitas dapat diketahui kesamaannya dengan menggunakan indeks kesamaan komunitas (IS). Pada perbandingan LOA 2013 dengan biodiversity strip dan LOA 2015 dengan LOA 2013 pada tingkat semai serta pancang memiliki nilai diatas $75 \%$. Pada perbandingan LOA 2016 dengan LOA 2013 nilai kesamaan komunitas diatas 75\%. Hal ini dapat disebabkan kesamaan jenis pohon yang dominan sebelum dilakukan penebangan sehingga terjadi kemiripan pada tingkat pertumbuhan semai dan pancang setelah dilakukan penebangan. Pada perbandingan LOA 2015 dengan LOA 2016 pada tingkat pertumbuhan pohon nilai indeks kesamaan komunitas memiliki nilai diatas $75 \%$. Hal ini dapat disebabkan adanya penyisihan pohon inti dengan jenis yang sama pada LOA 2016 dan 2015 sehingga adanya kemiripan pada tingkat pertumbuhan pohon.

Perkembangan pertumbuhan tegakan dapat dilihat dari komposisi jenis dan struktur tegakan hutan. Dari hasil analisis vegetasi yang dilakukan pada LOA 2013, 2015 dan 2016 dan biodiversity strip perkembangan setelah tebangan berdasarkan jenis pohon komersil dan jenis-nonkomersil pada kondisi biodiversity strip tegakan jenis komersil diameter kelas diameter 40 up jumlah pohon jenis komersil sebanyak 27 pohon/ha dengan volume 211,74 m3/ha. Pada kelas diameter $40 \mathrm{~cm}$ up perbandingan jumlah pohon jenis komersil pada kondisi biodiversity strip dengan kondisi hutan setelah penebangan mengalami peningkatan. Berturut-turut dari LOA 2013, 2015 dan 2016 pohon jenis komersil ditebang

Tabel 4 Nilai Indeks Keanekaragaman, Nilai Indeks Kekayaan Margalef dan Nilai Indeks Kemerataan pada berbagai tingkat permudaan pada Log Over Area dan biodiversity strip

\begin{tabular}{lllll}
\hline Kondisi Hutan & Tingkat Permudaan & Indeks Keanekaragaman & $\begin{array}{l}\text { Indeks } \\
\text { Kekayaan } \\
\text { Margalef }\end{array}$ & Indeks Kemerataan \\
& & \multicolumn{2}{c}{0} \\
\hline BDS & Semai & 1,55 & 1,92 & 0,67 \\
& Pancang & 2,53 & 4,32 & 0,64 \\
& Tiang & 2,06 & 2,91 & 0,86 \\
& Pohon & 2,74 & 4,41 & 0,93 \\
\hline LOA 2013 & Semai & 1,69 & 2,95 & 0,73 \\
& Pancang & 2,58 & 3,88 & 0,56 \\
& Tiang & 1,82 & 2,23 & 0,88 \\
& Pohon & 2,55 & 6,04 & 0,86 \\
\hline LOA 2015 & Semai & 1,93 & 2,89 & 0,84 \\
& Pancang & 2,26 & 4,89 & 0,56 \\
& Tiang & 2,41 & 3,64 & 0,94 \\
& Pohon & 2,83 & 5,63 & 0,88 \\
\hline LOA 2016 & Semai & 1,58 & 2,93 & 0,66 \\
& Pancang & 2,59 & 4 & 0,58 \\
& Tiang & 2,06 & 8,3 & 0,94 \\
& Pohon & 2,56 & 6,17 & 0,9 \\
\hline
\end{tabular}

Keterangan: $\mathrm{BDS}=$ Biodiversity strip (dilindungi), LOA = Log Over Area.

Tabel 5 Indeks kesamaan pada berbagai tingkat pertumbuan di LOA dan biodiversity strip

\begin{tabular}{clc}
\hline & Tingkat Permudaan & IS \\
\hline BDS $><$ LOA 2013 & Semai & 72,00 \\
& Pancang & 81,08 \\
& Tiang & 52,63 \\
& Pohon & 57,89 \\
\hline BDS $><$ LOA 2015 & Semai & 52 \\
& Pancang & 66,67 \\
& Tiang & 58,33 \\
& Pohon & 72,73 \\
\hline BDS $><$ LOA 2016 & Semai & 57,14 \\
& Pancang & 68,42 \\
& Tiang & 40,00 \\
& Pohon & 66,67 \\
\hline LOA 2013 >< LOA 2015 & Semai & 78,57 \\
& Pancang & 76,47 \\
& Tiang & 66,67 \\
& Pohon & 68,18 \\
\hline LOA 2013 $><$ LOA 2016 & Semai & 61,54 \\
& Pancang & 82,05 \\
& Tiang & 58,82 \\
& Pohon & 61,11 \\
\hline LOA 2015 $><$ LOA 2016 & Semai & 75,00 \\
& Pancang & 74,29 \\
& Tiang & 54,55 \\
& Pohon & 76,19 \\
\hline
\end{tabular}


berjumlah 15 pohon/ha, 19 pohon/ha, dan 14 pohon/ha. Dengan jumlah volume terbesar berada pada lokasi LOA 2016 sebesar 58,41 m3/ha dan terendah pada lokasi LOA 2015 sebesar 53,57 m3/ha. Hal ini menjukan bahwa tingkat kemampuan pemulihan permudaan pada tiap lokasi pengamatan berbeda-beda tergantung dari faktor perndukung biotik dan abiotik pada lokasi pengamatan.

Jumlah total individu pohon terbanyak berturut-turut berada pada biodiversity strip sebanyak 147 pohon/ha, LOA 2013 sebanyak 125 pohon/ha, LOA 2015 sebanyak 177 pohon/ha dan LOA 2016 sebanyak 122 pohon/ha. Pada kelas diameter 10-19 cm disemua kondisi hutan memiliki jumlah pohon (kerapatan pohon) paling tinggi daripada kelas diameter lainnya. Hal tersebut menunjukan bahwa pada kelas diameter 10-19 cm jumlah individu pohon/ha lebih banyak dibandingkan dengan kelas diameter lainnya. Jika dibandingkan biodiversity srtip dengan LOA tidak mengalami banyak perubahan karna penebangan hanya dilakukan pada jenis-jenis komersil.

Potensi pohon komersil masak tebang terbaik terdapat pada areal biodiversity strip. Hal ini dikarenakan lokasi pengamatan tidak mengalami gangguan seperti penebangan sehingga pohon masak tebang pada areal baik. Pada LOA 2016 potensi pohon komersil masak tebang terendah bila dibandingkan dengan LOA yang lain. Hal ini dikarenakan areal pengamatan belum lama selesai dilakukan penebangan sehingga recovery pada tegakan masih belum baik.

Pola pemanfaatan cahaya dapat dilihat dengan membuat stratifikasi tajuk. Stratifikasi tajuk pada IUPHHK-HA PT Diamond Raya Timber tergolong dalam 3 stratum yaitu stratum A, stratum B dan stratum C. Stratum A ditemukan hanya pada satu pohon yang berada diareal biodiversity strip, Stratum B ditemukan pada areal biodiversity strip dan LOA 2013 dan Stratum $\mathrm{C}$ ditemukan pada semua lokasi pengamatan. Perbedaan stratifikasi tajuk pada areal dikarenakan adanya kegiatan penebangan. Kondisi tegakan pada areal penebangan dalam proses pemulihan tegakan menuju hutan normal

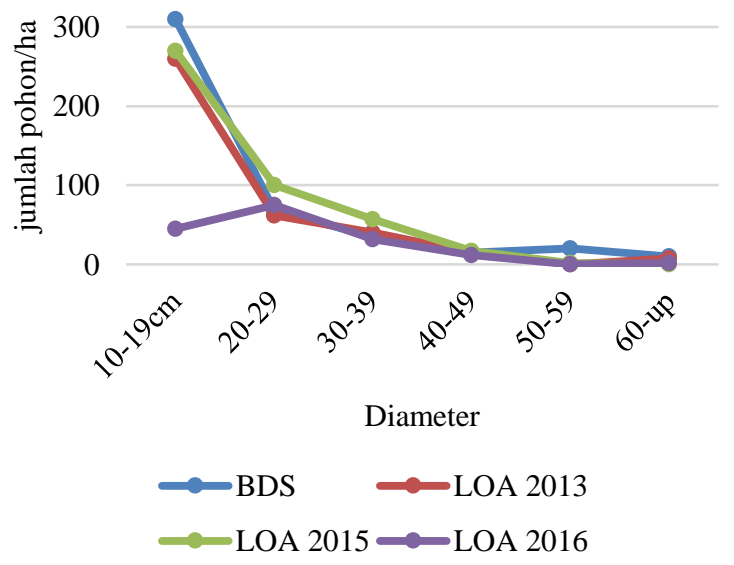

Keterangan: BDS = Biodiversity strip (dilindungi), LOA = Log Over Area

Gambar 2 struktur tegakan semua jenis pada areal hutan biodiversity strip (BDS) dan Log Over Area (LOA) karna kondisi struktur dan komposisi tegakan tidak berbeda jauh dengan areal biodiversity strip.

\section{SIMPULAN DAN SARAN}

\section{SIMPULAN}

Keanekaragaman pada areal pengamatan tergolong dalam kategori sedang untuk semua tingkat pertumbuhan. Tegakan memiliki kestabilan tergolong cukup stabil dilihat dari nilai indeks kemerataan yang didapat dari semua kondisi hutan. Areal tegakan masih dalam proses pemulihan untuk menuju kondisi normal. Potensi tegakan jenis komersil pada setiap tegakan menurun bila dibandingkan dengan areal biodiversity strip. Perbedaan potensi pada setiap areal diduga akibat kerusakan tegakan tinggal dan kemampuan pemulihan dari suatu tegakan hutan. Potensi pada biodiversity strip sebanyak 45 pohon/ha dengan volume sebesar 254,06 m3/ha. Pada kondisi hutan LOA 2013 terjadi penurunan potensi pohon masak tebang dengan jumlah pohon sebanyak 25 pohon/ha dan total volume sebesar 99,72 m3/ha. Pada kondisi hutan LOA 2015 pohon masak tebang sebanyak 19 pohon/ha yang memiliki total volume 53,57 m3/ha. Pada kondisi hutan LOA 2016 jumlah pohon masak tebang sebanyak 14 pohon/ha yang memiliki total volume $58,41 \mathrm{~m} 3 / \mathrm{ha}$.

\section{SARAN}

Jenis pohon inti yang ditinggalkan pada areal tersebut sebaiknya beragam guna menjaga keanekaragaman jenis pohon-pohon pada areal tersebut terutama jenis-jenis komersil.

\section{DAFTAR PUSTAKA}

Alrasjid H. 1983. Pengaruh penggunaan sistem silvikultur pohon induk terhadap perkembangan hutan payau simpang ulim, aceh (Laporan 416). Bogor (ID): Pusat Penelitian dan Pengembangan Hutan.

Ewel J, Conde L. 1980. Potencial Ecological Impact of Increased Intensity of Tropical Utilization. BIOTROP Special Publ.edisi (11): 70.

Gunawan H, Kobyashi S, Mizuno K Kono Y. 2012 Peat swamp forest type and their regeneration in Giam Siak Kecil-Bukit Batu Biosphere Reserve, Riau, East Sumatra, Indonesia. Japan (JPN): Kyoto University

Ludwig JA, Reynold JF. 1988. Statistical Ecology. New York (US): John Wiley and Sons.

Kusmana C, Istomo. 2005. Diktat Ekologi Hutan. Bogor (ID): Laboratorium Ekologi Hutan Fakultas Kehutanan IPB.

Magurran AE. 1998. Ecological Diversity and Its Measurement. London (EN): Croom Helm Ltd.

Ifo SA, Jean-Mariw M, Felix K, Josepsh Y, Saint FN, Leslie NOBK, Helischan M, Charlotte J Yannick B, Alima B M, Mackline M, Dulsan M S, Ronald O, Lenguiya R M, Yeto E M W, Brice C O, Loumeti J J. 2016. Tree Species Diversity, Richness, and 
Similarity in Intact and Degraded Forest in the Tropical Rainforest of the Congo Basin: Case of the Forest of Likouala in the Republic of Congo. International Journal of Forestry Research.

Mawazin, Subiakti A. 2013. Keanekaragaman dan Komposisi Jenis Permudaan Alam Hutan Rawa Gambut Bekas Tebangan di Riau (Spesies Diversity and Composition of Logged Over Peatswamp Forest in Riau). Jurnal Rehabilitasi Hutan. Vol.1:1. Hal 59- 73.

Mawazin. 2013. Tingkat Kerusakan Tegakan Tinggal di Hutan Rawa Gambut Sungai Kempeh - Sungai Air Hitam Laut, Jambi (Damage level of residual stand in peat swamp forest Sungai Kempeh - Sungai Air Hitam, Jambi). Jurnal Rehabilitasi Hutan. Vol. 1: 1. Hal $39-50$.

Meyer HA, D Stevensonand. 1961. Forest Management 2nd Edition. New York (US): The Ronald Press Company.

Misra R. 1980. Ecology Work Book. New Delhi (IND): Oxford \& IBH Publishing Co.

Mueller - Dombois D and H. Ellenberg. 1974. Aims and Methods of Vegetation Ecology. New York (US): John Willey and Sons, Inc.

Odum EP. 1993. Dasar-dasar ekologi. T. Samingan, penerjemah. Yogyakarta (ID): Gadjah Mada University Press. Terjemah dari: Fundamental of Ecology

Odum EP. 1971. Fundamental of Ecology. Philadelphia (USA); Saunders Company.

Orth D, MG Colette. 1996. "Especes dominantes et biodiversit 'e:' relation avec les conditions edaphiques et les pratiques agricoles' pour les prairies des marais du cotentin," Ecologi. 27:(3). 171-189.

Podong C, Poolsiri. 2013. Forest structure and species diversity of secondary forest after cultivation in relation to various sources at lower northern Thailand. Proceeding of the International Academy of Ecology and Environmental Sciences, Wanchai, Hong Kong 3(3), pp 208-218.

Richard PW. 1964. The Tropical Rain Forest: An Ecologycal Study. Cambrige (UK): Cambrige University Press Co.

Rio Y. 1996. Perkembangan komposisi jenis dan struktur tegakan tinggal hutan tropika basah di HPH PT Minas Pagai Lumber Corporation, Provinsi Sumatra Barat [Tesis]. Bogor (ID). Institut Pertanian Bogor.

Soerianegara I. 1994. Penelitian ekologi dan implementasinya dalam pegelolaan hutan di Indonesia. Bogor (ID): Forus Komunikasi Hasil Penelitian Kehutanan

Soerianegara I, Indrawan A. 2002. Ekologi Hutan Indonesia. Bogor (ID): Laboratorium Ekologi Hutan, Fakultas Kehutanan IPB.

Trichon V. 1997. 'H'et'erog'en'eit'e spatiale d'une for'et tropicale humide de Sumatra: effet de la topographie sur la structure floristique," Annales des Sciences Forestieres, INRA/EDP Sciences, vol. 54, no.5, pp. 431-446,

Wicaksono A. 2008. Struktur dan Komposisi Tegakan pada Areal Bekas Tebangan dengan Sistem Silvikultur Tebang Pilih Tanam Jalur [Skripsi]. Bogor (ID): Institut Pertanian Bogor. 